\title{
Climate change affects cell wall structure and hydrolytic performance of a tropical forage grass as an energy crop
}

\author{
Emanuelle Freitas ${ }^{1}$, Vinay Khatri ${ }^{2}$, Daniele Contin $^{1}$, Tassio Oliveira ${ }^{1}$, Alex Contato ${ }^{1}$, \\ Rosane Peralta ${ }^{3}$, Wanderley dos Santos ${ }^{4}$, Carlos Martínez ${ }^{1}$, Jack Saddler ${ }^{5}$, and Maria de \\ Lourdes Teixeira de Polizeli ${ }^{1}$ \\ ${ }^{1}$ Universidade de São Paulo \\ ${ }^{2}$ The University of British Columbia Faculty of Forestry \\ ${ }^{3}$ Universidade Estadual de Maringá \\ ${ }^{4}$ State University of Maringá \\ ${ }^{5}$ The University of British Columbia
}

November 25, 2020

\begin{abstract}
Forage grasses, such as Panicum maximum, are important alternatives of lignocellulosic biomass for bioethanol production. Thus, this study investigates whether future climate conditions could influence P. maximum cell wall structure and hydrolytic performance. A combined temperature-free air controlled and a free-air carbon dioxide enrichment (Trop-T-FACE) facility was used to investigated the isolated and combined effect of elevated atmospheric $\mathrm{CO} 2$ concentration (eC) (600 $\mu$ mol.mol-1) and elevated temperature (eT) by $2 @ \mathrm{C}$ more than the ambient temperature, on cell wall composition, cellulose crystallinity, accessibility, and hydrolysis yields. The elevated temperature treatments (eT and eT $+\mathrm{eC}$ ) exhibited the most pronounced effects. Warming reduced starch content and crystallinity index (CI) of cellulose while increased cellulose content. The fluorescent protein-tagged carbohydrate-binding modules analysis demonstrated that warming led to improvement in the total cellulose surface exposure/accessibility in $\mathrm{eT}$ and $\mathrm{eT}+\mathrm{eC}$ by $181 \%$ and $132 \%$, respectively. Consequently, glucan conversion yields were improved by 7.07 and $5.37 \%$, showing that warming led to lower recalcitrance in P. maximum biomass, which positively affect its use in biorefineries. Therefore, this work provides important information from an ecological and economic point of view, and might assist in the selection of tropical forage grasses efficiently adapted to climate changes with positive effect on bioenergy production.
\end{abstract}

\section{Climate change affects cell wall structure and hydrolytic performance of a tropical forage grass as an energy crop}

Emanuelle Neiverth de Freitas ${ }^{\mathrm{a}, \mathrm{c}}$, Vinay Khatri ${ }^{\mathrm{c}}$, Daniele Ribeiro Contin ${ }^{\mathrm{a}}$, Tássio Brito de Oliveiraa ${ }^{\mathrm{a}}$, Alex Graça Contato $^{\mathrm{a}}$, Rosane Marina Peralta ${ }^{\mathrm{b}}$, Wanderley Dantas dos Santos ${ }^{\mathrm{b}}$, Carlos Alberto Martinez y Huaman $^{\mathrm{a}}$, Jack Nicholas Saddler ${ }^{\mathrm{c}}$, Maria de Lourdes Teixeira de Moraes Polizelia*

${ }^{a}$ Department of Biology, FFCLRP, University of São Paulo, Ribeirão Preto, São Paulo, Brazil

${ }^{b}$ Department of Biochemistry, Maringá State University, Maringá, Paraná, Brazil

${ }^{c}$ Department of Wood Science, Faculty of Forestry, University of British Columbia, Vancouver, British Columbia, Canada

${ }^{*}$ Corresponding author: * Dr. Maria de Lourdes Teixeira de Moraes Polizeli, Biology Department, Faculty of Phylosophy, Science and letters of Ribeirão Preto, University of São Paulo 
Bandeirantes Av., 3.900. CEP: 14050-901.

Ribeirão Preto, São Paulo, Brazil

Tel.: +55-16-3315 4680, FAX: +55-16-33154886

E-mail: polizeli@ffclrp.usp.br

\title{
Funding
}

The authors thank Fundação de Amparo a Pesquisa do Estado de São Paulo (FAPESP) (Grant 2008/57908-6, 2008/58075-8, 2014/50884, 2018/07522-6, and Process 2017/23989-9) and Conselho Nacional de Desenvolvimento Científico e Tecnológico (CNPq) (Grants 446357/2015-4; 465319/2014-9, 301963/2017-7).

\begin{abstract}
Forage grasses, such as Panicum maximum, are important alternatives of lignocellulosic biomass for bioethanol production. Thus, this study investigates whether future climate conditions could influence P. maximum cell wall structure and hydrolytic performance. A combined temperature-free air controlled and a free-air carbon dioxide enrichment (Trop-T-FACE) facility was used to investigated the isolated and combined effect of elevated atmospheric $\mathrm{CO}_{2}$ concentration (eC) $\left(600 \mu \mathrm{mol} \cdot \mathrm{mol}^{-1}\right)$ and elevated temperature (eT) by $2 @ \mathrm{C}$ more than the ambient temperature, on cell wall composition, cellulose crystallinity, accessibility, and hydrolysis yields. The elevated temperature treatments $(\mathrm{eT}$ and $\mathrm{eT}+\mathrm{eC})$ exhibited the most pronounced effects. Warming reduced starch content and crystallinity index (CI) of cellulose while increased cellulose content. The fluorescent protein-tagged carbohydrate-binding modules analysis demonstrated that warming led to improvement in the total cellulose surface exposure/accessibility in eT and $\mathrm{eT}+\mathrm{eC}$ by $181 \%$ and $132 \%$, respectively. Consequently, glucan conversion yields were improved by 7.07 and $5.37 \%$, showing that warming led to lower recalcitrance in $P$. maximumbiomass, which positively affect its use in biorefineries. Therefore, this work provides important information from an ecological and economic point of view, and might assist in the selection of tropical forage grasses efficiently adapted to climate changes with positive effect on bioenergy production.
\end{abstract}

Key words: climate change, bioenergy, cell wall, lignocellulosic biomass, enzymatic saccharification, carbohydrate-binding modules.

\section{Acknowledgements}

The authors thank the postgraduate students and laboratory technicians who contributed to the work and the BIOPLAN-DBQ-UEM and the FPB/B group, Wood Science Department-UBC. Graphical abstract was created with BioRender.

\section{Introduction}

Climate change, resulting from the increasing emission of greenhouse gases, has a great impact on all living organisms. The $\mathrm{CO}_{2}$ atmospheric concentration $\left(\left[\mathrm{CO}_{2}\right]\right)$ is predict to increase to $550 \mu \mathrm{mol} \mathrm{mol}{ }^{-1}$ by 2050 while the average global temperature has risen by $0.85{ }^{\circ} \mathrm{C}$ comparing to pre-industrial era (IPCC 2019). In this way, lignocellulosic biomass (LCB) is a promising and sustainable method to reduce our carbon footprint meanwhile improving the efficiency of energy production to meet our ever-increasing energy demand (Fatmaet al. 2018). LCB consist of approximately $75 \%$ of polysaccharides that can be used, via fermentation, for second generation ethanol production; thus, it represent a renewable and abundant resource that is relatively cheap, highly accessible and expands the energy matrix (Singhvi \& Gokhale 2019).

However, agroecosystems growth, productivity and development might be strongly impact by the climate changes expected for the next decades (Gamage et al. 2018; Ruiz-Vera, Siebers, Jaiswal, Ort \& Bernacchi 2018; Ziaco, Truettner, Biondi \& Bullock 2018). Several studies have been conducted in order to predict the effect of increased $\left[\mathrm{CO}_{2}\right]$ and temperature on crop yields, growth and development (Ainsworth \& Ort 2010; Asseng et al. 2015; Zhaoet al. 2017). Nevertheless, much less is known about its effect on lignocellulosic 
biomass composition for bio-energy solutions and since they are one of the most potential alternative to obtain clean energy, their acclimation responses to climate change must be investigated.

Moreover, the changes in climate conditions are not expected to be isolated events i.e. both temperature and atmospheric $\left[\mathrm{CO}_{2}\right]$ are anticipated to increase simultaneously and studies interacting climate variables have not been adequately explored under field conditions. Plants response and vulnerability to isolated stresses are different from those resulted from combined stresses and will depend on their tolerance and mitigation ability to combined stress situations (Borjas-Ventura, Alves, de Oliveira, Martínez \& Gratão 2019). Therefore, in this study we characterize the lignocellulosic biomass composition and enzymatic hydrolysis of Panicum maximumperennial $\mathrm{C} 4$ grass (grown in elevated $\mathrm{CO}_{2}$ and temperature future conditions), which ultimately influence its ability to provide for a sustainable and cost-effective feedstock for biofuel production.

Among diverse LCB classification, fast-growing perennial C4 grasses have remarkable potential as a lignocellulosic feedstock for cellulosic ethanol production due to their high biomass yield, broad geographic adaption and low mineral-nutrient and pesticides inputs (van der Weijdeet al. 2013). Feedstocks with these characteristics contribute to the production of second-generation ethanol because they do not compete with our food resources, do not require extensive capital investment, and also can be used to avoid currently intermittent biofuel production, which make the final product more feasible specially during idle periods (Sosa et al. 2019a). P. maximum (Jacq. cv. Mombaça) is one of the most important C4 grass used as pasture in South America, especially Brazil, and also has significantly high efficiency in converting solar energy into biomass through photosynthesis (EMBRAPA 2014). Moreover, P. maximum grass represents an important alternative to sugarcane cellulosic ethanol, since it has lignocellulosic composition similar to sugarcane bagasse, as well as a bioethanol yield of 8571,0 L/ha compared to 8478,6 L/ha for sugarcane bagasse (Lima et al. 2014).

Enzymatic hydrolysis depends on the cellulose accessibility to cellulase enzymes. Therefore, it is utmost important to characterize lignocellulosic components' (i.e. cellulose and hemicellulose) accessibility and its impact on enzymatic hydrolysis. For this purpose, we used carbohydrate-binding modules (CBMs) that corresponds to a non-catalytic polysaccharide-recognition module of carbohydrate-active enzymes, such as glycoside hydrolases acting on glycosidic bonds. CBMs contributes to optimize the catalytic activity of plant cell wall hydrolases by increase the enzyme concentration on the carbohydrate surface (i.e. proximity effect) and by preferentially binding to specific substrate characteristics (i.e. substrate targeting) (Boraston, Bolam, Gilbert \& Davies 2004; Khatri, Hébert-Ouellet, Meddeb-Mouelhi \& Beauregard 2016). The high specificity of CBMs regarding to lignocellulosic polymers makes them attractive as probes to study the chemistry and structure variations on lignocellulosic biomass, cellulose accessibility to cellulase enzymes and verify the effect of applied treatment.(Cultures; Knox 2012; Oliveira, Carvalho, Domingues \& Gama 2015) Specifically, four distinctive fluorescent protein tagged CBMs (FP-CBM) were construct to detect alterations in amorphous cellulose, crystalline cellulose, xylan and mannan hemicellulose, respectively (Bombeck et al. 2017; Khatri, Meddeb-Mouelhi \& Beauregard 2018b; Gatt et al. 2019a).

In this study, P. maximum perennial $\mathrm{C} 4$ grass were grew under expected future climate conditions (i.e. elevated $\mathrm{CO}_{2}$ and temperature) under field conditions through a Trop-T-FACE system and characterized to study the change in their chemical composition, cell wall-bound phenolics, cellulose crystallinity, and lignocellulosic component accessibility to enzymes. Following this, enzymatic hydrolysis was performed to study the impact of elevated $\mathrm{CO}_{2}$ and temperature on potential production of bioethanol. Since the composition of the plant's organic matter, transpiration, photosynthesis, and metabolism can be influenced by climate temperature and $\left[\mathrm{CO}_{2}\right]$, we hypothesize that the climate change expected in the next years will influence the set of characteristics studied here, and thus affect P.maximum use for bioenergy production. We strongly believe that this work will enable more accurate projections of the responses of this important $\mathrm{C} 4$ crops species regarding to climate and productivity models and will also contribute for future decision-making in efficient production of bioenergy.

\section{Materials and methods}

Growth study site and Trop-T-Face system 
We evaluated the effect of two different climate change factors expected to impact on environment in the upcoming decades (i.e. elevate $\mathrm{CO}_{2}$ atmospheric concentrations $\left[\mathrm{CO}_{2}\right]$ and global average temperature increase) in the tropical grasslandPanicum maximum cv. Mombaça by using a Trop-T-FACE facility, located at the campus of the University of São Paulo, Ribeirão Preto, SP, Brazil. The following treatments were used: (a) ambient atmospheric $\left[\mathrm{CO}_{2}\right]$ and temperature (named here as Control: C) (b) ambient atmospheric $\left[\mathrm{CO}_{2}\right]$ and $+2{ }^{\circ} \mathrm{C}$ above ambient temperature (annotated as elevate temperature: eT), (c) 600 ppm atmospheric $\left[\mathrm{CO}_{2}\right]$ and ambient temperature (termed as elevate $\mathrm{CO}_{2}$ : eC) and (d) $600 \mathrm{ppm}$ atmospheric $\left[\mathrm{CO}_{2}\right]$ and $+2{ }^{\circ} \mathrm{C}$ above ambient temperature (designate as $\mathrm{eT}+\mathrm{eC}$ ). The Trop-T-Face system are described in details elsewhere (De Assis Prado, De Camargo-Bortolin, Castro \& Martinez 2016; Habermannet al. 2019b).

After 2 months, plants were clipped at $30 \mathrm{~cm}$ above the ground followed by the treatments with different levels of $\left[\mathrm{CO}_{2}\right]$ and temperature. After 24 days of experiment, at 12 P.M., P. maximumleaves were collected, milled at 20 mesh and storage in free humidity environment until analyses. Meteorological data of total solar radiation ( $\mathrm{Rad}$ ), air temperature (Tair), and relative air humidity $(\mathrm{Rh})$ during the whole growing season is discussed elsewhere (Habermann et al.2019b).

Lignocellulosic preparation and chemical composition

Lignocellulosic substrate preparation and the chemical composition of $P$. maximum under different climate conditions were determined using a modified Klason lignin method derived from the TAPPI standard method T222 om-88, as described elsewhere (Nakagame, Chandra \& Saddler 2010). The P. maximum extractives quantification was performed following the protocol proposed by National Renewable Energy Laboratory's (NREL) (Sluiter, Ruiz, Scarlata, Sluiter \& Templeton 2008).

Profile of cell wall-bound phenolics

The cell wall bound phenolics analysis was done as described elsewhere (Oliveira et al. 2019a). Quantification of cell wall-bound phenolics was accomplished by a HPLC system (Shimadzu@ Liquid Chromatograph, Tokyo, Japan).

Quantification of lignin and composition of monomers

To accurately quantify the lignin content in its monomer composition it is crucial to obtain a protein-free cell wall aiming to exclude protein and other UV-absorbing materials. The dry matter contained protein-free cell wall fraction as obtained according to a defined protocol (Ferrarese, MLL; Zottis, A; Ferrarese-Filho 2002). Lignin was quantified by the acetyl bromide assay described elsewhere (Oliveira et al.2019a) and alkaline nitrobenzene oxidation was used to determine lignin monomeric composition (Salvador et al. 2013).

Cellulose crystallinity

XRD analyses were performed on a Bruker D8-Advance X-ray diffractometer (Bruker, Germany), with Cobalt $\mathrm{K} \alpha$ radiation $(\lambda=0.178892 \mathrm{~nm}$ ) as described elsewhere (Jiang et al. 2020). Individual crystalline peaks were extracted by a curve-fitting method using the diffraction intensity profiles.

Non-structural carbohydrate content

Non-structural carbohydrates were quantified on leaves at 24 days of experiment collected at 12 P.M. of the respective day. The procedure used for reducing sugars content was based on (Somogyi 1945) and starch quantification was performed using an enzymatic assay (Amaral, Gaspar, Costa, Aidar \& Buckeridge 2007).

Enzymatic Hydrolysis

To avoid interference of soluble sugar during hydrolysis experiments, $P$. maximum samples were washed by immersion in $80^{\circ} \mathrm{GL}$ ethanol six times and then washed with water until the soluble sugars in the material were completely removed. All samples were then dried in an oven at $50^{\circ} \mathrm{C}$. The enzymatic hydrolysis of $P$. maximum (non-treated) was carried out applying enzyme cocktails Cellic CTec2 and Cellic HTec (Novozymes@) in the proportion of 9:1 (Ctec2:Htec ratio) (Jung, Yu, Eom \& Hong 2013) with a total amount of 20 $\mathrm{mg}$ of protein per gram of cellulose. The hydrolysis experiments were carried out at $2 \%(\mathrm{w} / \mathrm{v})$ solids loading 
in sodium acetate buffer $(50 \mathrm{mM}, \mathrm{pH} 4.8)$ at $50^{\circ} \mathrm{C}$ and $150 \mathrm{rpm}$. Subsequently to 72 hours hydrolysis, the enzymes were inactivated by heating the hydrolysis mixture for 10 minutes at $100{ }^{\circ} \mathrm{C}$. After centrifugation at $(16,000 \times \mathrm{g} / 10$ minutes $)$ the supernatants were collected and stored at $-20{ }^{\circ} \mathrm{C}$ for further analyses.

Sugar and protein assay

The quantitative analysis of glucose and xylose concentration in the hydrolysate was performed using a high-performance anion exchange chromatography (Dionex DX-3000, Sunnyvale, CA). The total glucan or xylan conversion of the substrate was calculated as a percentage of the theoretical glucan/xylan available in the substrate.

Holocellulose (cellulose + hemicellulose) accessibility using FTCM-depletion assay

The FTCM ( $F$ luorescent protein- $T$ agged $C$ arbohydrate-binding modules $M$ ethod) - depletion assay was used to evaluate the cellulose and hemicellulose surface accessibility in untreated and un-hydrolyzed $P$. $m a-$ ximumfibers grown in four different climate conditions (C, eT, eC and $\mathrm{eT}+\mathrm{eC})$. The assay was proceed as described elsewhere (Khatri et al. 2016; Khatri, Meddeb-Mouelhi, Adjallé, Barnabé \& Beauregard 2018a; Khatriet al. 2018b; Bombeck et al. 2017; Hébert-Ouellet et al. 2017; Gatt et al. 2019b; Mboowa, Khatri \& Saddler 2020) with four different FTCM probes: eGFP-CBM3a (GC3a) (fluorescent protein eGFP genetically linked with CBM3a), mCherry-CBM17 (CC17) (construct of the fluorescent protein mCherry and CBM17), mOrange2-CBM15 (OC15) (a chimera made of mOrange2 fluorescent protein and CBM15) and eCFP-CBM27 (CC27) (composed of eCFP and CBM27), targeting crystalline cellulose, amorphous cellulose (non-crystalline), xylan and mannan hemicellulose, respectively. The affinities and specificities of the FPCBM probes had been previously characterized by a solid-state depletion assay (SSDA), isothermal titration calorimetry (ITC) and affinity gel electrophoresis (AGE) (Khatri et al. 2016, 2018a b) Prior to FTCMdepletion assay, all substrates were incubated with bovine serum albumin (BSA) to block the lignin in order to prevent the non-specific binding of CBM probes to lignin (Khatri et al. 2018a) The difference between the binding isotherm of substrates without BSA blocking and with BSA blocking is summarized in Figure S1.

Statistics and numerical analysis

All tests were performed in triplicates, and the means and standard deviations were analyzed and indicated as the mean of three replicates \pm standard error of the means (SD). A principal component analysis (PCA) was performed to identify patterns in the dataset, the analysis was carried out in past (version 2.14). Analysis of variance (ANOVA) was performed to test the significance of the observed differences using the Graph-Pad Prism 8.0 software (San Diego, EUA). Differences among parameters were assessed by the Tukey test, and $p$ values [?] 0.05 were considered statistically significant.

\section{Results}

Biomass chemical composition

For all four studied energy crops (Figure S2), the biomass composition was analyzed for soluble extractives, ash, cellulose, hemicellulose and lignin contents and the results are summarized in Table 1. As hemicellulose from grasses is manly composed by Arabinoxylan (AXs) residues, the glucose from hemicellulose sources represents low quantities of the total glucan content, thus the cellulose content was considered for further discussions as the total glucan content of each group. The highest glucan content was found for eT $(30.2 \%)$ and $\mathrm{eT}+\mathrm{eC}(29.7 \%)$, followed by eC (27\%) and control (25.8\%) (Table 1). Significant differences (p[?]0.05) in glucan content were observed for $\mathrm{eT}$ and $\mathrm{eT}+\mathrm{eC}$ when compared to $\mathrm{C}$ and $\mathrm{eC}$ groups. There was no significant (p[?]0.05) difference between $\mathrm{C}$ and $\mathrm{eC}$ substrates. Lignin contents (Table 1) were quite similar for all studied climate conditions and no significant (p[?]0.05) difference was found among them, showing that the expected futuristic climate condition seems not to affect total lignin content on the studied forage grass. The hemicellulose content (Table 1) was calculated based on the monomeric sugars (xylose, arabinose, galactose and mannose) released after acid hydrolysis and was slightly (p[?]0.05) higher for eC conditions when compared with $\mathrm{C}$ and eT (Table 1). 
Furthermore, grasses with different treatments exhibited somewhat similar hemicellulose monosaccharide profiles, primarily composed of xylose, arabinose, and galactose (Figure 1). Moreover, mannose sugars were below detectable levels, which suggests that very low or no mannan was present in the hemicellulose and pectin fractions of the cell wall. A significant (p[?]0.05) difference was found in the monosaccharide profiles for eC treatment which exhibited more xylan (Fig. 1A) compared to $\mathrm{C}$ and more arabinose compared to other treatments (Figure 1B). On the other hand, no significant difference was found for galactose sugar in all the studied conditions (Fig. 1C). Figure 1D illustrate the xylan/arabinosil ratios that indicate the degree of arabinosyl substitution on grass's xylan backbone. In this work, we observed that the grasses in different climate conditions have Xyl:Ara ratio about 5:1, with significant difference among them (p[?]0.05). $\mathrm{eT}$ grasses exhibited the highest Xyl:Ara ratio and $\mathrm{eC}$ the lowest.

In addition, the PCA analysis shows that warming is the main driver of changes in P. maximum cell wall composition. It shows a clear separation of the warmed plots $(\mathrm{eT}$ and $\mathrm{eT}+\mathrm{eC}$ ) from the non-warmed plots $(\mathrm{C}$ and $\mathrm{eC})$ along the $\mathrm{PC} 1$ axis, explaining $62.31 \%$ of the variance in the cell wall composition and carbon storage (Figure 2A). It also indicates that the glucan content was the main responsible for these differences. No pattern was observed for the PC2 axis, which explained $19.61 \%$ of the distribution. The residual variation observed can be explained by the $\left[\mathrm{CO}_{2}\right](18.08 \%)$, as shown by the PC3 (Figure 2B).

Extractives are organic and inorganic molecules extracted from biomass by a polar or nonpolar solvent. They have a particular importance due to their low degradability, which can cause problems during lignocellulosic biomass processing (i.e. deconstruction and/or modification). Soluble ethanol extractives were of similar values, approximately $4 \%$, showing no significant difference among the tested groups (p[?]0.05).

\section{Lignin profile}

Besides measuring the lignin content (Table 1), we also analyzed the guaiacyl $(\mathrm{G})$, syringyl $(\mathrm{S})$ and $\mathrm{p}$ hydroxyphenyl $(\mathrm{H})$ monomeric content for lignin, for all climate conditions (Figure 3). The results show that $\mathrm{H}$ and $\mathrm{G}$ content is similar among the treatments (Figure 3A-B). However, we found higher (p[?]0.05) syringyl (S) content for eT and lower content for eT $+\mathrm{eC}$ treatment when compared to the other groups (Figure 3C). The $\mathrm{S}$ content observed was 5.12 and $3.5 \mu \mathrm{g} / \mathrm{mg}$ protein free cell for eT and eT+eC, respectively, compared to about $4.5 \mu \mathrm{g} / \mathrm{mg}$ protein free cell wall for $\mathrm{C}$ and $\mathrm{eC}$ treatments. Interestingly, differences were found in the $\mathrm{S} / \mathrm{G}$ ratio (Figure $3 \mathrm{D}$ ) among the studied climate conditions, in which eT treatment presented higher $\mathrm{S} / \mathrm{G}$ ratio (0.58) than $\mathrm{C}$ and $\mathrm{eC}$ conditions (p[?]0.05).

\section{Cell wall-bound phenolics}

The ferulic acid (FA) and $p$-coumaric ( $p$-CA) have an important role in cell wall structure and is described as an influencing factor in hydrolysis yields (Oliveira et al. 2019b), therefore the FA and $p$-CA content was analyzed to verify if it could interfere on hydrolysis of the different climate conditions studied (Figure S3). It was apparent that FA varied between 2.26 and $2.38 \mathrm{mg} / \mathrm{g}$ of biomass and $p$-CA between 3.04 and 3.41 $\mathrm{mg} / \mathrm{g}$ of biomass, with no significant difference found among the groups for both FA and $p$-CA ( $p$ [?] 0.05). Hence, FA and $p$-CA should not be an aspect that lead to differences in hydrolysis yields among the climate conditions studied in this work.

\section{Cellulose Crystallinity}

Crystallinity index (CI) is a quantitative representation that symbolize the relative amount of amorphous and crystalline regions of cellulose. As cellulose crystallinity is believed to have a role in its biological conversion, we then evaluated the CI for all climate conditions studied. The XRD graphs with the analysed peaks are represented in supplementary material (Figure S4). The CIs for $\mathrm{C}, \mathrm{eT}, \mathrm{eC}$ and $\mathrm{eT}+\mathrm{eC}$ were $71.7 ; 53.2 ; 64.7$ and $57.8 \%$, respectively. The elevated temperature treatments (eT and $\mathrm{eT}+\mathrm{eC})$ were the groups with lower crystallinity.

\section{Non-structural carbohydrate content}

Due to the importance of non-structural carbohydrates to the plant physiology, we estimated the total content 
of soluble reducing sugar and starch content after 24 DOE (Days of experiment), are shown in Figure 4. Soluble reducing sugars decreased by $21.45 \%$ and $27.4 \%$ (p[?]0.05) under eT and eT+eC, respectively, related to C (Fig. 4A). Regarding to the leaf starch content we found a 52.9 and $41.4 \%$ reduction (p[?]0.05) for eT and $\mathrm{eT}+\mathrm{eC}$, respectively, when compared to $\mathrm{C}$ (Fig. 4B) and a non-significant increase (16\%) in the leaf starch content for eC compared to C (Fig. 4B).

\section{Enzymatic saccharification}

Further the enzymatic saccharification of $P$. maximum grew under the four climate conditions $(\mathrm{C}, \mathrm{eT}, \mathrm{eC}$ and $\mathrm{eT}+\mathrm{eC}$ ) was performed to identify whether there would be any impact of climatic conditions on sugars releases for ethanol production (Figure 5). For this purpose, we used two commercial enzyme cocktails containing all the essential enzymes for lignocellulosic biomass deconstruction. We quantified the sugars released (glucose and xylose) by enzymatic hydrolysis in grasses without any pretreatment, as a way to avoid interference in biomass recalcitrance between forage grasses except climate conditions.

Glucan conversion (\%) at $72 \mathrm{~h}$ of hydrolysis from non-treated biomasses (2\% solid loading) was significantly higher (p[?]0.05) for warmed treatments (eT and $\mathrm{eT}+\mathrm{eC}$ ) with 43.9 and $43.2 \%$ of glucan conversion, whilst control (41\%) and eC (41.2\%) groups showed lower values of glucan hydrolysis (Fig. 5A). Moreover, these values represent a relative increment of 7.07 and $5.37 \%$ in glucan conversion for eT and eT+eC treatments, respectively when compared to $\mathrm{C}$ group. Furthermore, the percentage of xylan conversion for eT treatment (11.05\%) was also higher (p[?]0.05) than C (9.4\%), eC (9.6\%) and eT+eC (9.5\%) (Figure 5B), which represent a relative increment of $16.31 \%$ for eT when compared to the control group.

\section{Surface carbohydrate accessibility using FTCM-depletion assay}

Since hydrolysis depends on lignocellulosic components accessibility to the enzymes, we further study the change in the enzymatic hydrolysis data by evaluating $P$. maximum fibers accessibility using fluorescent protein-tagged carbohydrate-binding modules (FP-CBM). via four highly specific FP-CBM molecular probes (i.e. GC3a, CC17, OC15 and CC27). The FTCM-depletion assay of P. maximum fibers was well approximated by a single-site binding model as described elsewhere (Figure 6) (Khatri et al. 2018a; Gatt et al. 2019b; Mboowaet al. 2020). The parameters derived from these fits $\left(\mathrm{N}_{\mathrm{o}}\left(\mu \mathrm{moles} \mathrm{g}^{-1}\right), K_{\mathrm{a}}\left(\mu \mathrm{M}^{-1}\right), \Delta \mathrm{G}\right.$ (KJ $\left.\mathrm{mol}^{-1}\right)$ ) are summarized in Table S1.

The binding capacity or the total concentration of the available binding sites (No) on the control (C) fibers were $2.1 \pm 0.32 .2 \pm 0.7$ and $1.3 \pm 0.8$ for GC3a (crystalline cellulose accessibility recognition probe), CC17 (amorphous cellulose accessibility recognition probe) and OC15 (xylan accessibility recognition probe) probes, respectively (Table S1; Figure 6). It was apparent that there was no significant difference in the surface exposure/accessibility of crystalline cellulose, amorphous cellulose and xylan components of the biomass. On the other hand, no binding of $\mathrm{CC} 27$ (mannan recognition probe) probes were observed which complement the lack of mannan component in the $P$. maximum fibers. Furthermore, the total cellulose and hemicellulose accessibility could be derived by adding crystalline cellulose accessibility (i.e. No of GC3a) and amorphous cellulose accessibility (i.e. No of CC17), and xylan accessibility (i.e. No of OC15) with mannan accessibility (i.e. No of CC27), respectively (Table S1). The total cellulose accessibility was at least ${ }^{\sim} 3$-fold higher than total hemicellulose accessibility which suggest that cellulose exposure on the surface of $P$. maximum fibers were overwhelmingly higher than hemicellulose.

In the case of eT fibers, crystalline cellulose, amorphous cellulose and xylan accessibility increased by $267 \%$, $100 \%$ and $85 \%$, respectively, when compared to C. This increment also reflected in the $181 \%$ and $85 \%$ improvement in the total cellulose and total hemicellulose accessibility, respectively, when compared to its control counterpart (Figure 6; Table S1). In contrary, eC fibers did not exhibit any significant change in the holocellulose accessibility when compared to $\mathrm{C}$ group. Concerning to the combined impact of eT and eC, like eT, this condition improved the GC3a and CC17 bindings by $205 \%$ and $64 \%$, respectively, and as a result exhibited significantly higher $\%$ glucan conversion (Figure 5A). However, there was no significant improvement observed in the xylan accessibility. Furthermore, the lack of binding of mannan recognition probe $(\mathrm{CC} 27)$ to $\mathrm{eT}$, eC and $\mathrm{eT}+\mathrm{eC}$ biomass suggests that $\mathrm{FTCM}$ probes were highly specific towards their 
substrate and there was negligible non-specific interaction.

Lastly, in order to examine the robustness of relationship between bound probes and enzymatic hydrolysis observed here (i.e. type of correlation and correlation coefficient), a statistical analysis using all the value pairs (bound probes ( $\mu \mathrm{mol} / \mathrm{g}$ of biomass) vs glucan/xylan hydrolysis $(\%)$ generated in this study was performed. The results in the Figure 7 indicate that the total cellulose and hemicellulose accessibility, as detected by FTCM probes, were positively correlated with percent glucan and xylan hydrolysis, respectively. The Pearson's correlation coefficients for glucan and xylan hydrolysis were $\mathrm{R}=0.99, p<.001$, and $\mathrm{R}=0.99, p$ $<.001$, respectively, which supports the notion of a significant robust positive correlation.

Discussion

Biomass chemical composition

Lignocellulosic materials are manly composed by cellulose, hemicelluloses, and lignin. Cellulose is a linear homopolysaccharide composed of glucose monomers that can be converted into fermentable sugars through enzymatic hydrolysis (Silveira et al. 2015), which make feedstocks with higher glucan content likely to be favored in ethanol biorefinery industries from an economic point of view, since the cellulose content of the feedstocks is directly proportional to the ethanol yields under optimal processing conditions (Sosa et al.2019b). Hence, as elevated temperature treatments (eT and $\mathrm{eT}+\mathrm{eC})$ led to an increase in glucan content, warming treatment could have a positive effect on ethanol yields (Table 1).

In contrary to cellulose, the distribution of both lignin and hemicellulose in cell wall is described as a physical barrier that contributes to biomass recalcitrance by encapsulating cellulose microfibrils obstructing cellulase domains to adsorb on cellulose and initiate enzymatic hydrolysis (Khatri et al. 2016). Therefore, the hemicellulose content slightly higher for eC conditions may lead to lower saccharification yields (Table 1). The findings for hemicellulose content agrees with a transcriptome study which found that genes of a number of enzymes involved in hemicellulose and pectin biosynthesis such as NDP-sugar epimerases, UDP-glucose pyrophosphorylase (UGPase), glycosyltransferase family 43 (GT43) and others, had increased transcript levels in response to growth under elevated $\mathrm{CO}_{2}$ (Wei et al. 2013).

The lignin content found in this work are consistent with previous studies and indicates that $P$. maximum has similar percent composition of lignin with those reported for sugarcane bagasse, about $27.79 \%$ (Lima et al. 2014; Oliveira et al. 2019a). Therefore, lignin amount present in P. maximum does not represent a possible inconvenience (in terms of biomass deconstruction and modification) when compared to sugarcane bagasse (Table 1).

The results concerning to monosaccharide profiles agrees with the characteristics from type II hemicellulose cell wall of grasses is primarily composed of xylan with arabinofuranose (Araf)substitution of the b- $(1,4)$ xylose backbone by $\alpha$-linked, forming arabinoxylan (AXs) (Hatfield, Rancour \& Marita 2017). Another important parameter for biomass recalcitrance investigated in this work was the Xyl:Ara ratios. Substitution patterns on the xylan backbone (described here as Xyl:Ara ratio) has a robust relation with how strongly hemicellulose can form hydrogen bond to other cell wall polysaccharides, mainly lignin and cellulose, affecting structural properties of the cell wall as well as enzymatic hydrolysis yields (Hatfield et al.2017). In this sense, hydrolysis yields of eT might be favored, since this group exhibited higher $\mathrm{Xyl}$ : Ara, opposite to the eC group that had the highest degree of arabinosyl substitution (Figure 1).

By analyzing the above observed results for chemical composition of $P$. maximum LCB, it is probable to suggest that abiotic stress induced by climate changes can influence the cell wall composition of the forage grasses especially, the heat stress (i.e. eT) as showed by PCA analysis (Figure 2). Cell wall remodeling represents an important mechanism of stress tolerance, some reports related that important changes on cell wall might be driven by abiotic stress (Moura, Bonine, de Oliveira Fernandes Viana, Dornelas \& Mazzafera 2010; Tenhaken 2015; Wang, McFarlane \& Persson 2016) as a way to maintain growth and productivity. However, how much the stress will influence on plant physiological process depend on heating level and the tolerance mechanisms employed by the plant. 
Heat stress in most cases could results in water stress under modified environment situations (e.g., high temperatures and midday radiation) (Olivera Viciedo, de Mello Prado, Martínez, Habermann \& de Cássia Piccolo 2019). Under this scenario, C4 photosynthetic pathway plants increase their evaporative demands resulting in a temporary water stress. An evidence of water stress in $P$. maximum grown under warmer environment was found by Habermann et al., the author described a $15 \%$ increase in transpiration rates for P. maximum cv. Mombaça under eT environment, a slight reduction on solo water content (SWC), as well as decreased bulliform cells size, which store water (Habermannet al. 2019b). Furthermore, under eT conditions, P. maximum cv. Mombaça had an increment in amino acids content derived from pyruvate and oxaloacetate, reported to be related to the stress defenses (Wedow et al. 2019)

Lately some studies have been exploring the effect of many abiotic stresses under plant metabolism and some finds can help us to understand the higher glucan content for eT and eT $+\mathrm{eC}$ (Table 1). Most plants make physiological adjustments that contribute to the acclimation and survival under heat and water stress. For example, genes encoding Cellulose Synthase-Like (CSL) proteins, a family of proteins that are similar to the Cellulose synthases (CesAs), seems to play some role in cellulose synthesis and appears to be responsive to osmotic stress and salt stress, which could be a consequence of water stress. Interestingly, CSLD1, CSLD2, and CSLD3 genes were induced by increased salt conditions, leading to a cell wall deposition in Arabidopsis thaliana (Zhu et al. 2010). Cellulose deposition was also reported to happen in Zea mays stems under salt stress (Oliveiraet al. 2020). Furthermore, an increased level of expression of sucrose synthase and UDPglucose pyrophosphorylase genes was detected in cotton subject to drought stress, suggesting a possibly higher cellulose biosynthesis (Wei et al. 2013). Therefore, these results showed that changes in cell wall composition could play a role in the acclimation process of $P$. maximum allowing the plant to survive to non-lethal temperature through thermotolerance.

\section{Lignin Profile}

As the lignin content, the subunits ratio are highly variable between plant species, tissues, cell types, developmental stage and stress conditions and also has a role on the contribution of lignin to biomass recalcitrance (Li et al. 2010). The ratio of syringyl (S) and guaiacyl (G) units in lignin has been regarded as a factor that influences on recalcitrance to sugar release from energy crops enzymatic hydrolysis (Studer et al. 2011). This limit arises from the notion that during lignin biosynthesis coupling reactions in specific positions lead to polymers linked via $\mathrm{C}-\mathrm{O}$ bonds and $\mathrm{C}-\mathrm{C}$ bonds. The $\mathrm{C}-\mathrm{O}$ bonds are the most abundant and the key for lignin depolymerization, due to their labile nature. The $\mathrm{S}$ units are prone to formation of $\mathrm{C}-\mathrm{O}$ bond during lignin biosynthesis, which are more susceptible to cleavage (Anderson et al. 2019)

Therefore, biomass with higher S/G ratio, in this study represented by eT group, may represent a better choice for biorefinery purpose, since the lower G content allow that lignin structure to be easily modify increasing the accessibility to hydrolytic enzymes, and therefore, greater sugar release (Figure 3). Plants with higher S/G ratios shows that the negative influence of lignin on glucose release was less pronounced (Studer et al. 2011). The data found for eT group agrees with previous results that observed an increase in sinapic acid abundance under eT treatment, which was pointed as an impact of the eT on lignin compositions by increasing S-type concentrations (Wedowet al. 2019). Also, Zea mays plants under salt stress also exhibited higher $\mathrm{S} / \mathrm{G}$ ratios in roots and stem which could be the case of eT treatment (Oliveira et al. 2020).

\section{Cell wall-bound phenolics}

Produced in the phenylpropanoid pathway the hydroxycinnamic acids also known as ferulic acid (FA) and $p$ -coumaric ( $p-\mathrm{CA}$ ) have a carboxylic group at the end of their propenyl group in contrast with the alcohol function of monolignols that are produced later (Tobimatsu \& Schuetz 2019). Due to this fact, feruloyl and p-coumaroyl residues can further esterified to arabinose from the arabinoxylans (AXs) of the type II cell wall. The FA esterified with arabinosyl residue of AXs is able to connect with lignin by ether-linkage or dimerize with other FA-arabinoxylan acting as a universal connector between cell wall polymers. These reaction results in cross-linking among the cell wall polymers, which can reduce enzymatic hydrolysis efficiency, by blocking the accessibility and attack of hydrolases (Oliveira et al.2019b). Furthermore, these acids performs a key 
role in cessation of cell growth, anchoring lignin in cell wall polysaccharides and restricting the accessibility of plant pathogens (de Oliveira et al. 2015).

The FA average content for P. maximum is relatively lower compared with sugarcane bagasse (8.0 to 17.0 $\mathrm{mg} / \mathrm{g}$ ) and Perennial ryegrass (Lollium perenne ) shoot (Gagic et al. 2010; Masarin et al. 2011) (Figure S3). The lower FA content of $P$. maximum should be an advantage since cell well digestibility and FA content are negatively correlated. In addition, the FA and $p$ - CA contents agrees with those ones reported by Oliveira et al. (2019a) that observed a FA content about $2 \mathrm{mg} / \mathrm{g}$ AIR (Alcohol Insoluble Residue) and about $3.4 \mathrm{mg} / \mathrm{g}$ AIR for $p$-CA for cv. Mombaca.

\section{Cellulose Crystallinity}

Cellulose structure is generally divided into two regions, the first one is called amorphous cellulose and is described to have molecular order, the second one is high level of molecular order and is called crystalline cellulose. The enzymatic and microbial hydrolysis of regions are easier and faster than the crystalline regions, since amorphous region is able to adsorb water (Karimi \& Taherzadeh 2016). Although there are many factors affecting the cellulose hydrolysis as available surface area, and degree of polymerization, the cellulose crystallinity is reported to be a limiting step on cellulose conversion due to its recalcitrance, which means that lower CI results in higher bioconversion rates for lignocelluloses feedstocks (Poornejad, Karimi \& Behzad 2013; Ostovareh, Karimi \& Zamani 2015). In addition, many studies showed that enzyme adsorption, including the non-catalytic cellulose binding module (CBM) and catalytic glycosyl hydrolase system, generally declined as cellulose crystallinity increased (Jeoh, T., Ishizawa, C. I., Davis, M. F., Himmel, M. E., Adney, W. S., \& Johnson 2007). In this way, eT and eT+eC, due to its lower CI, should be the climate conditions that must results in higher cellulose conversions (Figure S4).

The effect of temperature on reducing cellulose crystallinity for $P$. maximum could rely on the thermotolerances mechanisms employed under water stress experienced in warming treatments. Reactive oxygen species (ROS) are commonly observed as a plant response to abiotic stress. In general, they are used as a cosubstrate by cell wall peroxidases, which lead to cross-linking increasement between phenolic compounds and hemicellulose polymers (Miller, Suzuki, cCiftci-yilmaz \& Mittler 2010). However, if ROS production continues and all cross-linkable substrates have already been used by peroxidases, this allows the production of OH-radical that is involved in cell wall loosing process, by cleaving sugar bonds in plant polysaccharides, action similar to enzymes like expansins that are reported to promote amorphogenesis in cellulose microfibrils (Tenhaken 2015). This loosing process promote by ROS is reported to be a tolerance mechanism employed by plants to overcome the growth arrest under abiotic stress, and could also lead to enhancement in hydrolytic performance by, as described in this study, reducing the CI.

\section{Non-structural carbohydrate content}

Carbohydrates are molecules with important role in signaling pathways as well as in the tolerance of plant species to abiotic stresses (Gangola \& Ramadoss 2018). The intercellular content of sugars regulates multiple functions in source and sink tissues including photosynthetic performance, gene expression and enzyme activities (Koch 1996). In this work, both alcohol soluble reducing sugars and starch content were found to be reduced in warmed treatments (eT and $\mathrm{eT}+\mathrm{eC}$ ) (Figure 4). These results agrees with others Panicum maximum studies, the first one was a metabolome study of intracellular content that reported many carbohydrates (arabionose, frutose, galactose, maltose, ribose, xylose and melobiose) with increased abundance under eT (Wedow et al.2019), showing that these carbohydrates are being thansportated as signaling molecules, which could be a response for the abiotic strees when the plants are subjected to a warmer environment. The second one found larger quantity and size on starch grains in chloroplasts of bundle cells for $\mathrm{eC}$ treatment and minor starch grains for $\mathrm{eT}$ and $\mathrm{eT}+\mathrm{eC}$ (Habermann et al. 2019b a).

The increased starch content in leaves for eC treatment is a response for the higher carbon assimilation found in eC, showing thatPanicum maximum is not saturated under $\mathrm{CO}_{2}$ atmospheric concentration (Habermann et al. 2019b). Concerning to $\mathrm{eT}$ and $\mathrm{eT}+\mathrm{eC}$, as previously discussed, warming treatments led to a stress statement in plants that demands more energy. In this case, starch is described to be involved in plant's 
reactions to abiotic stress and it is the principal carbohydrate stored in source organs that is quickly remobilized to provide energy to sink tissues, consequently reducing its content in source tissues (Thalmann \& Santelia 2017). These results suggest that starch was degraded and transported as sucrose to sinks organs, therefore, its content in leaves (source organs) is reduced under eT treatment.

\section{Enzymatic saccharification}

The efficiency of enzymatic saccharification which is the key step in the bioconversion of lignocellulose biomass to ethanol can be influenced by several factors related to the biomass recalcitrance, such as the cellulose crystallinity, available surface area, degree of hemicellulose matrix polymerization, lignin distribution, etc (Novy et al.2019). As discussed earlier, elevated temperature treatments (eT and eT+eC) could play an important role in improving percent glucan content, reducing biomass recalcitrance by lowering cellulose crystallinity and minimizing Xyl/Ara (Figure 1) and S/G ratio (Figure 3), which ultimately might result in a less polymerized matrix between hemicellulose elements and also between hemicellulose and lignin. All the above-mentioned results, led to improved accessibility to the hydrolytic enzymes for warming treatments, and thus, higher cellulose conversion into glucose during saccharification process (Figure 5). Even though the differences in conversion rates were not much pronounced, minimal differences on sugar release could have an important impact on the biorefineries from an economic point of view.

Moreover, it is important to note that no pretreatment was applied in this study that is why the conversion rates observed after enzymatic hydrolysis were quite low. Thus, by applying efficient pretreatment on $P$. maximum grasses the glucan and xylan conversion rates could be further improved, since it facilitates the access of glycoside hydrolases to polysaccharides (Agbor, Cicek, Sparling, Berlin \& Levin 2011).

\section{Surface carbohydrate accessibility using FTCM-depletion assay}

Hydrolysis is strongly impacted by the accessibility of enzymes to the lignocellulosic components. According to the FP-CBM data, it was apparent that growing $P$. maximum under elevated temperature increased the holocellulose accessibility (Figure 6; Table S1) and as a result the enzymatic hydrolysis of both glucan and xylan component (Figure 5). This also compliment above reported higher glucan chemical composition (Table 1), lower crystallinity (Figure S4), elevated xylan/arabinose (Figure 1) and S/G ratio (Figure 3) for eT condition. Nonetheless, for eC fibers no difference was found in holocellulose accessibility compared to $\mathrm{C}$ group, which was reflect in the any significant improvement in the $\%$ glucan and $\%$ xylan conversion for eC. Moreover, this is likely due to the observed significantly lower xylan/arabinose (Figure 1) and S/G ratio (Figure 3), since both hemicellulose and lignin contribute to biomass recalcitrance. Regarding to $\mathrm{eT}+\mathrm{eC}$, it followed similar trends as eT condition for total cellulose accessibility, which depicted that elevated temperature plays a dominant role over elevated $\mathrm{CO}_{2}$ by suppressing the inherent changes occurred via eC environmental condition. The role of warming treatments (eT and $\mathrm{eT}+\mathrm{eC})$ in increase cellulose accessibility can be also related to ROS production under abiotic stress, as discussed in Section 4.4, which opens up the plant cell wall by mediated cleavage of polymer chains and provides catalytic enzymes with improved accessibility to the glycosidic linkages within the sugar polymers .

\section{Conclusions}

Abiotic stress effects plant cell wall architecture although the impact depends on the plant genotype, species, age and on the timing and intensity of the stress. Among all the studied climate conditions eT exhibited higher percent glucan composition, S/G ratio, higher total cellulose accessibility, and hence elevated enzymatic hydrolysis. In contrary, eC showed higher percent total hemicellulose composition (which was due to higher arabinose content), lower S/G ratio, significantly lower total cellulose accessibility and therefore lower enzymatic hydrolysis yield. Furthermore, eT $+\mathrm{eC}$ conditions followed similar trends as eT conditions, which depicted that elevated temperature plays a dominant role over elevated $\mathrm{CO}_{2}$. Moreover, state-ofthe-art FTCM-depletion assay facilitated to study the surface exposure/accessibility in real time to better understand the enzymatic hydrolysis. Our data provide clearly evidences that $P$. maximum cell wall has several mechanisms of adjustment under abiotic stress induced by expected futuristic climate conditions, which could positively affect its use for bioenergy purpose. However, the work has gone beyond the concerns 
over the carbon emissions and climate change brought by fossil fuels, this work has also come up with a potential alternative of lignocellulosic biomass for cellulosic ethanol production, which may contribute to better-informed decisions on energy options for the future.

\section{Declaration of competing interest}

The authors have no conflict of interest.

\section{Author contributions}

E.N.F., M.L.T.M.P. and C.A.M.H. designed the research. E.N.F., V.K., D.R.C. and A.G.C., performed the experiments. T.B.O assisted in PCA and statistical analysis. E.N.F., M.L.T.M.P., C.A.M.H., R.M.P., W.D.S and J.N.S. assisted the experimental design, analyzed and discussed the data. E.N.F wrote the manuscript with contributions from all the coauthors. All authors approved the final version of the manuscript.

\section{References}

Agbor V.B., Cicek N., Sparling R., Berlin A. \& Levin D.B. (2011) Biomass pretreatment: Fundamentals toward application.Biotechnology Advances 29, 675-685.

Ainsworth E.A. \& Ort D.R. (2010) How Do We Improve Crop Production in a Warming World? Plant Physiology 154, 526-530.

Amaral L.I.V. do, Gaspar M., Costa P.M.F., Aidar M.P.M. \& Buckeridge M.S. (2007) Novo metodo enzimatico rapido e sensivel de extracao e dosagem de amido em materiais vegetais. Hoehnea 34, 425-431.

Anderson E.M., Stone M.L., Katahira R., Reed M., Muchero W., Ramirez K.J., .. Roman-Leshkov Y. (2019) Differences in S/G ratio in natural poplar variants do not predict catalytic depolymerization monomer yields. Nature Communications 10, 1-10.

Asseng S., Ewert F., Martre P., Rotter R.P., Lobell D.B., Cammarano D., .. Zhu Y. (2015) Rising temperatures reduce global wheat production. Nature Climate Change 5 , 143-147.

De Assis Prado C.H.B., De Camargo-Bortolin L.H.G., Castro E. \& Martinez C.A. (2016) Leaf Dynamics of Panicum maximum under Future Climatic Changes. PLOS ONE 11, 1-17.

Bombeck P.L., Khatri V., Meddeb-Mouelhi F., Montplaisir D., Richel A. \& Beauregard M. (2017) Predicting the most appropriate wood biomass for selected industrial applications: Comparison of wood, pulping, and enzymatic treatments using fluorescent-tagged carbohydrate-binding modules. Biotechnology for Biofuels $10,1-14$.

Boraston A.B., Bolam D.N., Gilbert H.J. \& Davies G.J. (2004) Carbohydrate-binding modules: Fine-tuning polysaccharide recognition.Biochemical Journal 382, 769-781.

Borjas-Ventura R., Alves L.R., de Oliveira R., Martinez C.A. \& Gratao P.L. (2019) Impacts of warming and water deficit on antioxidant responses in Panicum maximum Jacq. Physiologia Plantarum165, 413-426.

Cultures P.T. Chapter 1 Plant Tissue Cultures. Methods715 , 1-20.

EMBRAPA (2014) Relatorio de Avaliacao dos impactos das tecnologias geradas pela Embrapa Gado de Corte-Capim Mombac,a. Embrapa Gado Corte.

Fatma S., Hameed A., Noman M., Ahmed T., Shahid M., Tariq M., ... Tabassum R. (2018) Lignocellulosic Biomass: A Sustainable Bioenergy Source for the Future. Protein 83 Peptide Letters 25 , 148-163.

Ferrarese, MLL; Zottis, A; Ferrarese-Filho O. (2002) Protein-free lignin quantification in soybean (Glycine $\max$ ) roots. Biologia 57 , 541-543.

Gagic M.J.F.K.R.M., Mace W., Sun X.Z., Harrison S., Knapp K., Jahufer M.Z.Z., .. Bryan G. (2010) Genetic improvement of fibre traits in perennial ryegrass. Proceedings of the New Zealand Grassland Association , $71-78$. 
Gamage D., Thompson M., Sutherland M., Hirotsu N., Makino A. \& Seneweera S. (2018) New insights into the cellular mechanisms of plant growth at elevated atmospheric carbon dioxide concentrations.Plant Cell and Environment 41, 1233-1246.

Gangola M.P. \& Ramadoss B.R. (2018) Sugars Play a Critical Role in Abiotic Stress Tolerance in Plants. In Biochemical, Physiological and Molecular Avenues for Combating Abiotic Stress Tolerance in Plants . pp. 17-38. Elsevier.

Gatt E., Khatri V., Bley J., Barnabe S., Vandenbossche V. \& Beauregard M. (2019a) Enzymatic hydrolysis of corn crop residues with high solid loadings: New insights into the impact of bioextrusion on biomass deconstruction using carbohydrate-binding modules. Bioresource Technology 282 , 398-406.

Gatt E., Khatri V., Bley J., Barnabe S., Vandenbossche V. \& Beauregard M. (2019b) Enzymatic hydrolysis of corn crop residues with high solid loadings: New insights into the impact of bioextrusion on biomass deconstruction using carbohydrate-binding modules. Bioresource Technology 282, 398-406.

Habermann E., Dias de Oliveira E.A., Contin D.R., Delvecchio G., Viciedo D.O., de Moraes M.A., ... Martinez C.A. (2019a) Warming and water deficit impact leaf photosynthesis and decrease forage quality and digestibility of a C4 tropical grass. Physiologia Plantarum165 , 383-402.

Habermann E., San Martin J.A.B., Contin D.R., Bossan V.P., Barboza A., Braga M.R., ... Martinez C.A. (2019b) Increasing atmospheric CO 2 and canopy temperature induces anatomical and physiological changes in leaves of the $\mathrm{C} 4$ forage species Panicum maximum. PLoS ONE14, 1-25.

Hatfield R.D., Rancour D.M. \& Marita J.M. (2017) Grass cell walls: A story of cross-linking. Frontiers in Plant Science 7 .

Hebert-Ouellet Y., Meddeb-Mouelhi F., Khatri V., Cui L., Janse B., Macdonald K. \& Beauregard M. (2017) Tracking and predicting wood fibers processing with fluorescent carbohydrate binding modules. Green Chemistry 19 , 2603-2611.

Intergovernmental Panel on Climate Change (2019) Carbon Dioxide: Projected emissions and concentrations.

Jeoh, T., Ishizawa, C. I., Davis, M. F., Himmel, M. E., Adney, W. S., \& Johnson D.K. (2007) Cellulase digestibility of pretreated biomass is limited by cellulose accessibility. Biotechnology and Bioengineering $\mathbf{9 8}$ , 112-122.

Jiang J., Carrillo-Enriquez N.C., Oguzlu H., Han X., Bi R., Song M., ... Jiang F. (2020) High Production Yield and More Thermally Stable Lignin-Containing Cellulose Nanocrystals Isolated Using a Ternary Acidic Deep Eutectic Solvent. ACS Sustainable Chemistry 83 Engineering8 , 7182-7191.

Jung C.D., Yu J.H., Eom I.Y. \& Hong K.S. (2013) Sugar yields from sunflower stalks treated by hydrothermolysis and subsequent enzymatic hydrolysis. Bioresource Technology 138, 1-7.

Karimi K. \& Taherzadeh M.J. (2016) A critical review of analytical methods in pretreatment of lignocelluloses: Composition, imaging, and crystallinity. Bioresource Technology 200 , 1008-1018.

Khatri V., Hebert-Ouellet Y., Meddeb-Mouelhi F. \& Beauregard M. (2016) Specific tracking of xylan using fluorescent-tagged carbohydrate-binding module 15 as molecular probe. Biotechnology for Biofuels9 , 1-13.

Khatri V., Meddeb-Mouelhi F., Adjalle K., Barnabe S. \& Beauregard M. (2018a) Determination of optimal biomass pretreatment strategies for biofuel production: Investigation of relationships between surfaceexposed polysaccharides and their enzymatic conversion using carbohydrate-binding modules. Biotechnology for Biofuels11, 1-16.

Khatri V., Meddeb-Mouelhi F. \& Beauregard M. (2018b) New insights into the enzymatic hydrolysis of lignocellulosic polymers by using fluorescent tagged carbohydrate-binding modules. Sustainable Energy and Fuels 2, 479-491. 
Knox J.P. (2012) In situ detection of cellulose with carbohydrate-binding modules, 1st ed. Elsevier Inc.

Koch K.E. (1996) CARBOHYDRATE-MODULATED GENE EXPRESSION IN PLANTS.Annual Review of Plant Physiology and Plant Molecular Biology47 , 509-540.

Li X., Ximenes E., Kim Y., Slininger M., Meilan R., Ladisch M. \& Chapple C. (2010) Lignin monomer composition affects Arabidopsis cell-wall degradability after liquid hot water pretreatment.Biotechnology for Biofuels 3, 1-7.

Lima M.A., Gomez L.D., Steele-King C.G., Simister R., Bernardinelli O.D., Carvalho M.A., ... Polikarpov I. (2014) Evaluating the composition and processing potential of novel sources of Brazilian biomass for sustainable biorenewables production. Biotechnology for Biofuels 7 , 1-19.

Masarin F., Gurpilhares D.B., Baffa D.C.F., Barbosa M.H.P., Carvalho W., Ferraz A. \& Milagres A.M.F. (2011) Chemical composition and enzymatic digestibility of sugarcane clones selected for varied lignin content.Biotechnology for Biofuels 4, 1-10.

Mboowa D., Khatri V. \& Saddler J.N. (2020) The use of fluorescent protein-tagged carbohydrate-binding modules to evaluate the influence of drying on cellulose accessibility and enzymatic hydrolysis. RSC Advances $10,27152-27160$.

MILLER G., SUZUKI N., CIFTCI-YILMAZ S. \& MITTLER R. (2010) Reactive oxygen species homeostasis and signalling during drought and salinity stresses. Plant, Cell \& Environment 33 , 453-467.

Moura J.C.M.S., Bonine C.A.V., de Oliveira Fernandes Viana J., Dornelas M.C. \& Mazzafera P. (2010) Abiotic and Biotic Stresses and Changes in the Lignin Content and Composition in Plants. Journal of Integrative Plant Biology 52, 360-376.

Nakagame S., Chandra R.P. \& Saddler J.N. (2010) The effect of isolated lignins, obtained from a range of pretreated lignocellulosic substrates, on enzymatic hydrolysis. Biotechnology and Bioengineering105 , 871-879.

Novy V., Aissa K., Nielsen F., Straus S.K., Ciesielski P., Hunt C.G. \& Saddler J. (2019) Quantifying cellulose accessibility during enzyme-mediated deconstruction using 2 fluorescence-tagged carbohydrate-binding modules. Proceedings of the National Academy of Sciences of the United States of America 116 , 22545-22551.

Oliveira C., Carvalho V., Domingues L. \& Gama F.M. (2015) Recombinant CBM-fusion technology - Applications overview. Biotechnology Advances 33, 358-369.

de Oliveira D.M., Finger-Teixeira A., Rodrigues Mota T., Salvador V.H., Moreira-Vilar F.C., Correa Molinari H.B., ... Dantas dos Santos W. (2015) Ferulic acid: A key component in grass lignocellulose recalcitrance to hydrolysis. Plant Biotechnology Journal13 , 1224-1232.

Oliveira D.M., Mota T.R., Grandis A., de Morais G.R., de Lucas R.C., Polizeli M.L.T.M., ... dos Santos W.D. (2019a) Lignin plays a key role in determining biomass recalcitrance in forage grasses.Renewable Energy $147,2206-2217$.

Oliveira D.M., Mota T.R., Oliva B., Segato F., Marchiosi R., Ferrarese-Filho O., ... dos Santos W.D. (2019b) Feruloyl esterases: Biocatalysts to overcome biomass recalcitrance and for the production of bioactive compounds. Bioresource Technology 278, 408-423.

Oliveira D.M., Mota T.R., Salatta F. V., Sinzker R.C., Končitíková R., Kopečný D., ... dos Santos W.D. (2020) Cell wall remodeling under salt stress: Insights into changes in polysaccharides, feruloylation, lignification, and phenolic metabolism in maize. Plant, Cell $\mathscr{E}$ Environment .

Olivera Viciedo D., de Mello Prado R., Martínez C.A., Habermann E. \& de Cássia Piccolo M. (2019) Short-term warming and water stress affectPanicum maximumJacq. stoichiometric homeostasis and biomass production. Science of the Total Environment 681, 267-274. 
Ostovareh S., Karimi K. \& Zamani A. (2015) Efficient conversion of sweet sorghum stalks to biogas and ethanol using organosolv pretreatment. Industrial Crops and Products 66 , 170-177.

Poornejad N., Karimi K. \& Behzad T. (2013) Improvement of saccharification and ethanol production from rice straw by NMMO and [BMIM][OAc] pretreatments. Industrial Crops and Products41 , 408-413.

Ruiz-Vera U.M., Siebers M.H., Jaiswal D., Ort D.R. \& Bernacchi C.J. (2018) Canopy warming accelerates development in soybean and maize, offsetting the delay in soybean reproductive development by elevated CO2 concentrations. Plant Cell and Environment 41, 2806-2820.

Salvador V.H., Lima R.B., dos Santos W.D., Soares A.R., Böhm P.A.F., Marchiosi R., .. Ferrarese-Filho O. (2013) Cinnamic Acid Increases Lignin Production and Inhibits Soybean Root Growth. PLoS ONE8, $1-10$.

Silveira M.H.L., Morais A.R.C., Da Costa Lopes A.M., Olekszyszen D.N., Bogel-Łukasik R., Andreaus J. \& Pereira Ramos L. (2015) Current Pretreatment Technologies for the Development of Cellulosic Ethanol and Biorefineries. ChemSusChem $8,3366-3390$.

Singhvi M.S. \& Gokhale D. V. (2019) Lignocellulosic biomass: Hurdles and challenges in its valorization. Applied Microbiology and Biotechnology 103, 9305-9320.

Sluiter A., Ruiz R., Scarlata C., Sluiter J. \& Templeton D. (2008) Determination of Extractives in Biomass: Laboratory Analytical Procedure (LAP); Issue Date 7/17/2005.

Somogyi M. (1945) A new reagente for the determination of sugars.J Biol Chem 160 , 61-63.

Sosa L.L., Jozami E., Oakley L.J., Montero G.A., Ferreras L.A., Venturi G. \& Feldman S.R. (2019a) Using C4 perennial rangeland grasses for bioenergy. Biomass and Bioenergy 128, 105299.

Sosa L.L., Jozami E., Oakley L.J., Montero G.A., Ferreras L.A., Venturi G. \& Feldman S.R. (2019b) Using C4 perennial rangeland grasses for bioenergy. Biomass and Bioenergy 128, 105299.

Studer M.H., DeMartini J.D., Davis M.F., Sykes R.W., Davison B., Keller M., ... Wyman C.E. (2011) Lignin content in natural populus variants affects sugar release. Proceedings of the National Academy of Sciences of the United States of America 108, 6300-6305.

Tenhaken R. (2015) Cell wall remodeling under abiotic stress.Frontiers in Plant Science 5 .

Thalmann M. \& Santelia D. (2017) Starch as a determinant of plant fitness under abiotic stress. New Phytologist 214, 943-951.

Tobimatsu Y. \& Schuetz M. (2019) Lignin polymerization: how do plants manage the chemistry so well? Current Opinion in Biotechnology56, 75-81.

Wang T., McFarlane H.E. \& Persson S. (2016) The impact of abiotic factors on cellulose synthesis. Journal of Experimental Botany $\mathbf{6 7}, 543-552$.

Wedow J.M., Yendrek C.R., Mello T.R., Creste S., Martinez C.A. \& Ainsworth E.A. (2019) Metabolite and transcript profiling of Guinea grass (Panicum maximum Jacq) response to elevated [CO 2 ] and temperature. Metabolomics 15, 1-13.

Wei H., Gou J., Yordanov Y., Zhang H., Thakur R., Jones W. \& Burton A. (2013) Global transcriptomic profiling of aspen trees under elevated [CO2] to identify potential molecular mechanisms responsible for enhanced radial growth. Journal of Plant Research 126 , 305-320.

van der Weijde T., Alvim Kamei C.L., Torres A.F., Vermerris W., Dolstra O., Visser R.G.F. \& Trindade L.M. (2013) The potential of C4 grasses for cellulosic biofuel production. Frontiers in Plant Science4 , 1-18.

Zhao C., Liu B., Piao S., Wang X., Lobell D.B., Huang Y., ... Asseng S. (2017) Temperature increase reduces global yields of major crops in four independent estimates. Proceedings of the National Academy of 
Sciences of the United States of America 114, 9326-9331.

Zhu J., Lee B.H., Dellinger M., Cui X., Zhang C., Wu S., ... Zhu J.K. (2010) A cellulose synthase-like protein is required for osmotic stress tolerance in Arabidopsis. Plant Journal 63 , 128-140.

Ziaco E., Truettner C., Biondi F. \& Bullock S. (2018) Moisture-driven xylogenesis in Pinus ponderosa from a Mojave Desert mountain reveals high phenological plasticity. Plant, Cell \& Environment41, 823-836.

\section{Figures Legends}

Figure 1: Monosaccharide profiles of Panicum maximum in different climate conditions: Control (C), Elevated Temperature $(\mathrm{eT})$, Elevated $\mathrm{CO}_{2}(\mathrm{eC})$ and combined treatments $(\mathrm{eT}+\mathrm{eC})$. Mean values $\pm \mathrm{SD}$ $(\mathrm{n}=3)$ marked with different letters above bars indicate statistical differences between treatments (p[?]0.05, Tukey's test).

Figure 2 : Principal Component Analysis of Panicum maximum cell wall composition in different climate conditions: Control (C), Elevated Temperature (eT), Elevated $\mathrm{CO}_{2}(\mathrm{eC})$ and combined treatments (eT+eC).

Figure 3 : Lignin monomers of Panicum maximum in different climate conditions: Control (C), Elevated Temperature (eT), Elevated $\mathrm{CO}_{2}(\mathrm{eC})$ and combined treatments $(\mathrm{eT}+\mathrm{eC})$. CW: Cell Wall. Mean values +- SD $(\mathrm{n}=3)$ marked with different letters above bars indicate statistical differences between treatments (p[?]0.05, Tukey's test).

Figure 4 : Carbohydrates content in leaves of Panicum maximum. Reducing sugars (A) and starch (B). Treatments: Control (C), Elevated Temperature (eT), Elevated $\mathrm{CO}_{2}(\mathrm{eC})$ and combined treatments $(\mathrm{eT}+\mathrm{eC})$. Mean values $+-\mathrm{SD}(\mathrm{n}=3)$ marked with different letters above bars indicate statistical differences between treatments (p[?]0.05, Tukey's test).

Figure 5: Glucose (A) and Xylan (B) conversion of untreatedPanicum maximum after enzymatic saccharification at $72 \mathrm{~h}$ and $2 \%$ solid content. Treatments: Control (C), Elevated Temperature (eT), Elevated $\mathrm{CO}_{2}$ $(\mathrm{eC})$ and combined treatments $(\mathrm{eT}+\mathrm{eC})$. Mean values $+-\mathrm{SD}(\mathrm{n}=3)$ marked with different letters above bars indicate statistical differences between treatments (p[?]0.05, Tukey's test).

Figure 6 : Binding isotherm of FTCM-depletion assay probes: GC3a (A), CC17 (B), OC15 (C) and CC27 (D) to $\mathrm{C}, \mathrm{eT}, \mathrm{eC}$ and $\mathrm{eT}+\mathrm{eC}$ substrates at $25 \mathrm{degC}$ in a $20 \mathrm{mM}$ Tris- $\mathrm{HCl}(\mathrm{pH} 7.5)$ buffer containing $20 \mathrm{mM}$ $\mathrm{NaCl}, 5 \mathrm{mM} \mathrm{CaCl}{ }_{2}$. Treatments: Elevated Temperature (eT), Elevated $\mathrm{CO}_{2}(\mathrm{eC})$ and combined treatments $(\mathrm{eT}+\mathrm{eC})$.

Figure 7: Correlation between accessibility (total cellulose accessibility (A) as detected by FTCM probes $(\mathrm{GC3a}+\mathrm{CC} 17)$ and total hemicelluloses accessibility (B) as detected by FTCM probes (OC15 + CC27)) and percent glucan/xylan hydrolysis.

\section{Hosted file}

TABLE AND FIGURES, Freitas et al., 2020-PCE.pdf available at https://authorea.com/users/ 378625/articles/495078-climate-change-affects-cell-wall-structure-and-hydrolyticperformance-of-a-tropical-forage-grass-as-an-energy-crop 